\title{
Changes in Language Function and Recovery-Related Prognostic Factors in First-Ever Left Hemispheric Ischemic Stroke
}

\author{
Kyung Ah Kim, $\mathrm{MD}^{1}$, Jung Soo Lee, $\mathrm{PhD}^{1}$, Won Hyuk Chang, $\mathrm{MD}$, $\mathrm{PhD}^{1}$, \\ Deog Young Kim, $\mathrm{MD}, \mathrm{PhD}^{2}$, Yong-Il Shin, $\mathrm{MD}, \mathrm{PhD}^{3}$, Soo-Yeon Kim, $\mathrm{MD}, \mathrm{PhD}^{3}$, \\ Young Taek Kim, $\mathrm{PhD}^{4}$, Sung Hyun Kang, $\mathrm{PhD}^{4}$, Ji Yoo Choi, $\mathrm{MS}^{4}$, Yun-Hee Kim, MD, $\mathrm{PhD}^{1,5}$
}

\begin{abstract}
${ }^{1}$ Department of Physical and Rehabilitation Medicine, Center for Prevention and Rehabilitation, Heart Vascular Stroke Institute, Samsung Medical Center, Sungkyunkwan University School of Medicine, Seoul; ${ }^{2}$ Department of Rehabilitation Medicine and Research Institute of Rehabilitation Medicine, Yonsei University College of Medicine, Seoul; ${ }^{3}$ Department of Rehabilitation Medicine, Pusan National University Yangsan Hospital, Pusan National University School of Medicine, Busan; ${ }^{4}$ Division of Chronic Disease Control, Center for Disease Prevention, Korea Centers for Disease Control and Prevention, Osong; ${ }^{5}$ Samsung Advanced Institute for Health Sciences \& Technology, Sungkyunkwan University, Seoul, Korea
\end{abstract}

Objective To investigate longitudinal changes in language function in left-hemispheric ischemic stroke patients as well as factors that influence language recovery until 1 year after stroke onset.

Methods We analyzed data from 235 patients with first-ever left-hemispheric ischemic stroke. All patients completed the Korean version of the Frenchay Aphasia Screening Test (K-FAST) at 7 days (T1), 3 months (T2), 6 months (T3), and 1 year (T4) after stroke onset. Repeated measures analysis of variance (ANOVA) was used to investigate changes in language function between time points. Subgroup analysis was performed according to the K-FAST scores at T1. Stroke lesion volume was assessed using diffusion tensor images, and involvement of language-related brain regions was examined. Multiple regression analysis was used to analyze factors influencing improvement of K-FAST score. Results The K-FAST scores at T1, T2, T3, and T4 differed significantly $(\mathrm{p}<0.05)$. In the subgroup analysis, only the severe group showed continuous significant improvement by 1 year. Factors that negatively influenced improvement of language function were the age at onset, initial National Institutes of Health Stroke Scale (NIHSS) score, and initial K-FAST score, whereas education level and stroke lesion volume positively affected recovery. Involvement of language-related brain regions did not significantly influence long-term language recovery after ischemic stroke. Conclusion Recovery of language function varied according to the severity of the initial language deficit. The age at stroke onset, education level, initial severity of aphasia, initial NIHSS score, and total stroke lesion volume were found to be important factors for recovery of language function.

Keywords Stroke, Aphasia, Prognosis, Stroke volume, Rehabilitation

Department of Physical and Rehabilitation Medicine, Samsung Medical Center, 81 Ilwon-ro, Gangnam-gu, Seoul 06351, Korea. Tel: +82-2-3410-2824, Fax:+82-2-3410-0052, E-mail: yun1225.kim@samsung.com, yunkim@skku.edu

ORCID: Kyung Ah Kim (http://orcid.org/0000-0003-4990-6789); Jung Soo Lee (http://orcid.org/0000-0001-9439-0166); Won Hyuk Chang (http://orcid. org/0000-0002-4969-7895); Deog Young Kim (http://orcid.org/0000-0001-7622-6311); Yong-Il Shin (http://orcid.org/0000-0001-7894-0930); Soo-Yeon Kim (http://orcid.org/0000-0001-5679-0126); Young Taek Kim (http://orcid.org/0000-0003-0139-7620); Sung Hyun Kang (http://orcid.org/0000-00016745-8196); Ji Yoo Choi (http://orcid.org/0000-0001-7925-3577); Yun-Hee Kim (http://orcid.org/0000-0001-6101-8851).

(a) This is an open-access article distributed under the terms of the Creative Commons Attribution Non-Commercial License (http://creativecommons.org/ licenses/by-nc/4.0) which permits unrestricted noncommercial use, distribution, and reproduction in any medium, provided the original work is properly cited. Copyright ( 2019 by Korean Academy of Rehabilitation Medicine 


\section{INTRODUCTION}

Deficit of language function, or aphasia, is one of the main sequelae of stroke, occurring in $28 \%-38 \%$ of stroke patients [1]. Aphasia has a large effect on daily living, lowers the return to work rate, and affects the quality of life of stroke patients $[2,3]$. Because of the social burden and disability that aphasia can cause, many studies have attempted to identify predictable measures of aphasia recovery. Age, sex, educational level, lesion size and location such as the superior temporal gyrus (STG), and treatment-related factors, have been discussed as factors predicting post-stroke aphasia recovery [4]. Many studies have hypothesized that stroke location, especially the Broca's and Wernicke's areas, is related to prognosis of language recovery, based on the traditional WernickeLichtheim language model $[3,5,6]$. However, the brain regions reported to be related to language prognosis are variable and not yet defined $[5,6]$.

Recovery from aphasia occurs in various ways, such as the recruitment of perilesional neural resources and refinement of language processing function in the nondominant right hemisphere [7]. Moreover, the development of neuroimaging techniques has revealed limitations in the traditional language model and shown that language is a function of complex processing among core brain regions [3]. Predicting language recovery in aphasia patients by defining prognostic factors remains unresolved. The main limitations of previous studies are small sample sizes and the absence of long-term follow-up.

In this study, we examined 235 first-ever ischemic stroke patients to investigate changes in longitudinal language function up until 1 year after onset and to identify factors influencing language recovery. The relationship between stroke lesion and recovery of language function was also examined.

\section{MATERIALS AND METHODS}

\section{Study design}

This study used data from the Korean Stroke Cohort for Function and Rehabilitation (KOSCO). The KOSCO study is a 10-year, long-term follow-up study of stroke patients using a prospective multicenter design to investigate residual disability, activity limitation, and quality of life in patients who experienced a first-ever stroke. Patients with ischemic and hemorrhagic stroke were included, while patients with transient ischemic attack were excluded. The detailed rationale and protocol of KOSCO have been previously described [8].

\section{Study participants}

The KOSCO data from three participating hospitals, collected from August 2012 to May 2015, were reviewed. A total of 1,287 patients with a left hemispheric lesion were selected. Of the 1,287 patients, 624 (48.5\%) with preserved language function (Korean version of the Frenchay Aphasia Screening Test [K-FAST] score >25) and $274(21.3 \%)$ with a coinciding right hemispheric stroke lesion were excluded. Another 125 (10.1\%) patients were excluded owing to missing follow-up assessments, and 29 (2.3\%) patients were excluded owing to missing magnetic resonance imaging (MRI) data. Altogether, a total of 235 first-time stroke patients were included in the final analysis (Fig. 1).

\section{Demographic and clinical characteristics}

Data on demographic and clinical characteristics including age, sex, obesity, hypertension, hyperlipidemia, diabetes mellitus, atrial fibrillation, family history of stroke, education level, the National Institutes of Health Stroke Scale (NIHSS) score at admission, smoking status, and alcohol use were collected from the KOSCO study records. Included comorbidities were recorded according to the following definitions: hypertension (systolic blood pressure $>160 \mathrm{mmHg}$, diastolic blood pressure $>90$ $\mathrm{mmHg}$, or history of hypertension or medical treatment), diabetes mellitus (elevated blood glucose level >126 mg/ day or history of diabetes or medical treatment), atrial fibrillation (documented by standard electrocardiogram [ECG], long-term ECG, or history of atrial fibrillation or medical treatment), hyperlipidemia (low-density lipoprotein $>160 \mathrm{mg} / \mathrm{dL}$, elevated total cholesterol level $>240$ $\mathrm{mg} / \mathrm{dL}$, or history of hyperlipidemia or medical treatment), and obesity (body mass index $[\mathrm{BMI}] \geq 25$ ). Education level was classified based on the highest diploma that the patient acquired as follows: no formal education, primary education (primary school diploma, 1-6 years of education), secondary education (middle or high school diploma, 7-12 years of education), and higher education (university or graduate school diploma, more than 13 years of education). The NIHSS scores were grouped into 


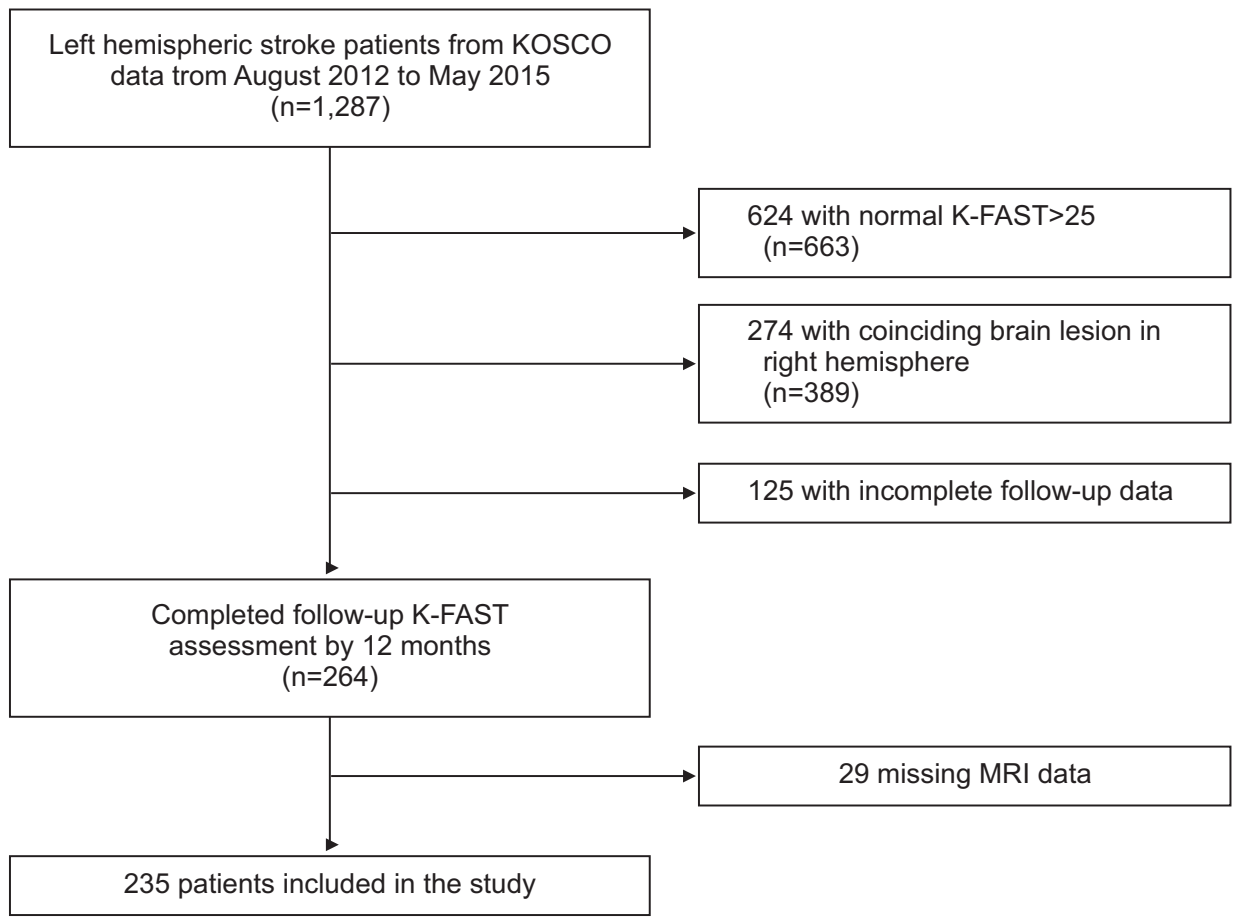

Fig. 1. CONSORT flow diagram for the study. KOSCO, Korean Stroke Cohort for Function and Rehabilitation; K-FAST, Korean version of the Frenchay Aphasia Screening Test; MRI, magnetic resonance imaging.

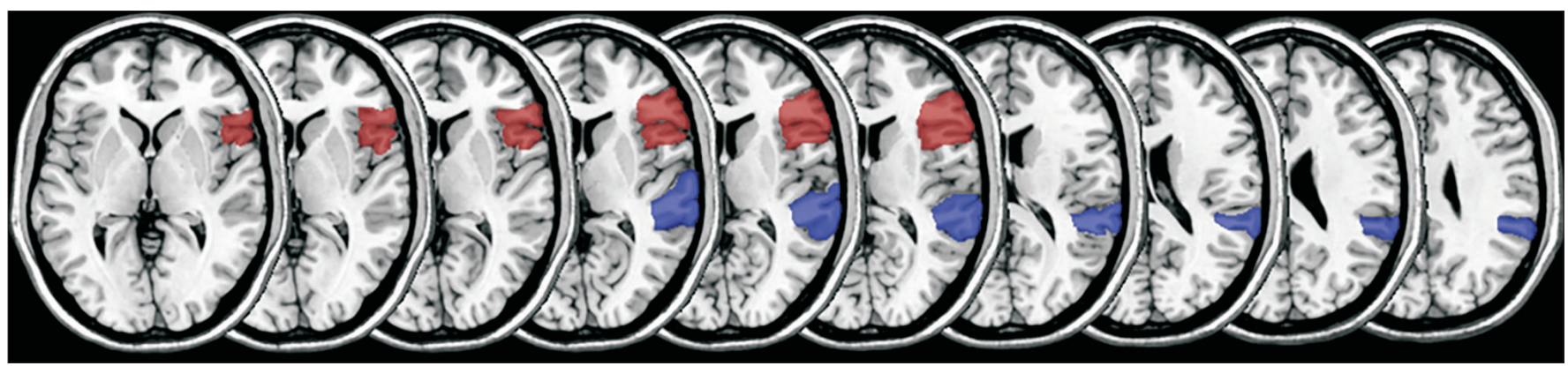

Fig. 2. Magnetic resonance imaging mapping of aphasia-related regions of interest with MRIcro software.

three categories: mild (NIHSS score 0-5), moderate (NIHSS score 6-13), and severe (NIHSS score $\geq 14$ ) [9].

\section{Neuroimaging assessment}

Stroke lesion volume and involvement of languagerelated cortical lesions were assessed. To determine language-related cortex involvement, Broca's area and Wernicke's area (posterior third of the STG) were selected as regions of interest (ROIs) (Fig. 2). The MRI scans performed at the time of admission were reviewed. Each lesion was manually drawn on diffusion-weighted imaging with lesion mapping software (MRIcro software version 1.4; Chris Rorden's Neuropsychology Lab, Columbia, SC, USA). The lesion volume of each patient was extracted using a binarized lesion mask. The lesion area was as- signed a value of 1 in the binarized lesion mask with lesion mapping software. The lesion volume was calculated by multiplying the number of voxels assigned a value of 1 in the binarized lesion mask by the voxel volume and converted into $\mathrm{cm}^{3}$. Before the results were analyzed, brain MRI scans from 30 randomly selected patients were used to verify lesion volume reproducibility. ROI involvement and lesion volume were assessed by two blind readers, and inter-rater reliability was evaluated prior to statistical analysis. Interclass correlation tests (ICC) for lesion volume, assessed by two blind readers, showed excellent reliability $(p>0.9)$. Interclass correlation tests for the involvement of Broca's area and Wernicke's area (posterior third of the STG) were 0.882 and 0.845 , respectively. 


\section{Language function assessment}

Language function was evaluated using the K-FAST, which includes assessment of comprehension, verbal expression, reading, and writing. Patients were assessed with K-FAST at 7 days, 3 months, 6 months, and 1 year after stroke onset. Furthermore, to evaluate changes in language function according to the severity of the initial aphasia, participants were categorized into three groups according to the initial K-FAST score: mild (K-FAST score 20-25), moderate (K-FAST score 11-19), and severe (KFAST score 0-10) [10]. In this study, we defined the primary outcome of aphasia as delta K-FAST score: the difference between the initial K-FAST and the 1-year K-FAST scores.

\section{Statistical analysis}

For statistical analysis, we used descriptive statistics for demographic and clinical characteristics. Nominal and ordinal data obtained from a baseline review of medical records and initial stroke features were assessed using frequency analysis. Scale factors were analyzed using average analysis. Differences in demographic and clinical data among severity groups were analyzed using Pearson $\chi^{2}$ or Fisher exact test for categorical variables and the Kruskal-Wallis rank test for numerical variables that did not meet normality assumptions. Inter-rater reliability in measuring lesion volume and determining ROI involvement was calculated with ICC. Repeated measures ANOVA was conducted to assess the difference in language function at 7 days, 3 months, 6 months, and 1 year in the total study population, and in subgroups. To correct for baseline differences in variables among the groups, age, initial K-FAST score, total stroke lesion volume, obesity level, education level, initial NIHSS score, and languagerelated cortical region involvement were included as covariates when conducting ANOVA. Bonferroni correction was used in the post-hoc analysis of ANOVA. McNemar test was conducted to evaluate differences in patient distribution in the severity groups after 1 year. To determine related factors for language function recovery in terms of delta K-FAST, linear regression was initially conducted, and multiple regression analysis was performed for significant values. Additionally, variance inflation factor (VIF) values were investigated for the multicollinearity of independent variables, and the cutoff value was set to less than 5 . The p-values less than 0.05 were considered statistically significant. All analyses were conducted using SPSS version 24.0 (IBM, Armonk, NY, USA).

\section{RESULTS}

\section{Participant characteristics}

Among the groups, there were significant differences in the age at onset, stroke lesion volume, initial K-FAST score, level of obesity, education level, initial NIHSS severity, and language-related cortical region involvement. Full patient demographic and clinical characteristics are shown in Table 1.

\section{Changes in language function}

The mean values of K-FAST scores assessed at 7 days, 3 months, 6 months, and 1 year after onset were 15.5 \pm 7.6 , $19.8 \pm 8.1,21.1 \pm 7.8$, and 22.0 \pm 7.6 , respectively, and differed significantly among time points $(\mathrm{p}<0.05)$ (Fig. $3 \mathrm{~A})$. However, sub-group analysis revealed that only the severe group had significant differences in mean K-FAST scores among time points $(\mathrm{p}<0.05)$ (Fig. 3B). Mean KFAST scores among groups were significantly different at all assessment time points, using an independent samples t-test with post-hoc Bonferroni correction $(\mathrm{p}<0.01)$. Improvement of language function was also observed by the shift of patient distribution in the K-FAST severity groups after 1 year. At the initial assessment, 39.0\% of cases were categorized as mild; $\mathbf{3 4 . 3 \%}$, as moderate; and $26.7 \%$, as severe. After 1 year, only $8.5 \%$ of cases were categorized as severe and $40.3 \%$ were found to have normal language function (K-FAST score $>25$ ) (Fig. 3C). All groups had significant changes in distribution at 1 year $(\mathrm{p}<0.05)$.

\section{Factors related to aphasia improvement}

Linear regression indicated the age at onset, obesity level, education level, initial NIHSS score, initial K-FAST score, total lesion volume, and language-related cortical region involvement as factors affecting delta K-FAST. Among the above-mentioned factors, when assessed with multivariate analysis, age at onset, education level, initial NIHSS score, initial K-FAST score, and total lesion volume area were identified as factors influencing the recovery of language function (Table 2). Among the variables included for multivariate analysis, there were no variables with multicollinearity $(\mathrm{VIF}<5)$. Age at onset, 
Table 1. Demographical and clinical characteristics

\begin{tabular}{|c|c|c|c|c|}
\hline Characteristic & $\begin{array}{l}\text { Mild group } \\
(\mathrm{n}=91)\end{array}$ & $\begin{array}{l}\text { Moderate group } \\
(\mathbf{n}=\mathbf{8 1})\end{array}$ & $\begin{array}{l}\text { Severe group } \\
(n=63)\end{array}$ & p-value \\
\hline Age (yr) & $65.2 \pm 12.3$ & $67.5 \pm 12.2$ & $67.9 \pm 11.7$ & $<0.001^{* * *}$ \\
\hline Sex, male & $69(75.8)$ & $49(60.5)$ & $38(60.3)$ & 0.052 \\
\hline Ever smoking & $32(35.2)$ & $20(24.7)$ & $23(36.5)$ & 0.223 \\
\hline Ever drinking & $47(51.6)$ & $27(33.3)$ & $26(41.3)$ & 0.051 \\
\hline \multicolumn{5}{|l|}{ Risk factors of stroke } \\
\hline Hypertension & $44(48.4)$ & $45(55.6)$ & $38(60.3)$ & 0.323 \\
\hline Diabetes mellitus & $23(25.3)$ & $14(17.3)$ & $14(22.2)$ & 0.444 \\
\hline Atrial fibrillation & $6(6.6)$ & $10(12.3)$ & $6(9.5)$ & 0.433 \\
\hline Hyperlipidemia & $11(12.1)$ & $12(14.8)$ & $9(14.3)$ & 0.859 \\
\hline Obesity & $2(2.2)$ & $2(2.5)$ & $7(11.1)$ & $0.032^{*}$ \\
\hline Family history & $2(2.2)$ & $6(7.4)$ & $1(1.6)$ & 0.161 \\
\hline \multicolumn{5}{|l|}{ Education level } \\
\hline No formal education & $3(3.3)$ & $7(8.6)$ & $4(6.3)$ & 0.301 \\
\hline Primary education ( $1-6$ yr) & $10(11.0)$ & $23(28.4)$ & $17(27.0)$ & $0.009^{* *}$ \\
\hline Secondary education (7-12 yr) & $56(61.5)$ & $43(53.1)$ & $35(55.6)$ & 0.516 \\
\hline Higher education ( $\geq 13 \mathrm{yr}$ ) & $22(24.2)$ & $8(9.9)$ & $7(11.1)$ & $0.018^{*}$ \\
\hline Initial K-FAST score & $23.0 \pm 1.6$ & $15.5 \pm 2.7$ & $5.59 \pm 3.7$ & $<0.001^{* * *}$ \\
\hline \multicolumn{5}{|l|}{ NIHSS initial score } \\
\hline Mild (0-5) & $84(92.3)$ & $70(86.4)$ & $39(61.9)$ & $<0.001^{* * *}$ \\
\hline Moderate (6-13) & $7(7.7)$ & $11(13.6)$ & $18(28.6)$ & $0.002^{* *}$ \\
\hline Severe $(\geq 14)$ & $0(0.0)$ & $0(0.0)$ & $6(9.5)$ & $0.000^{* * *}$ \\
\hline Total stroke lesion volume $\left(\mathrm{cm}^{3}\right)$ & $5.0 \pm 8.8$ & $5.8 \pm 10.6$ & $13.8 \pm 20.4$ & $<0.001^{* * *}$ \\
\hline \multicolumn{5}{|c|}{ Language-related cortical region involvement } \\
\hline Broca's area & $2(2.2)$ & $3(3.7)$ & $9(14.3)$ & $0.008^{*}$ \\
\hline Wernicke's area & $11(12.1)$ & $15(18.5)$ & $8(12.7)$ & 0.438 \\
\hline Both & $0(0.0)$ & $1(1.2)$ & $3(3.2)$ & 0.190 \\
\hline
\end{tabular}

Values are presented as mean \pm standard deviation or number (\%).

NIHSS, National Institutes of Health Stroke Scale; K-FAST, Korean version of the Frenchay Aphasia Screening Test. ${ }^{*} \mathrm{p}<0.05,{ }^{* *} \mathrm{p}<0.01,{ }^{* * *} \mathrm{p}<0.001$, statistically significant among the mild, moderate, and severe groups.

initial NIHSS score, and initial K-FAST score were shown to negatively affect language function recovery, while education level and stroke lesion volume positively influenced language function improvement during the 1 year after stroke. For the final multivariate regression model, adjusted $\mathrm{R}^{2}$ value was 0.395 , with a $\mathrm{p}$-value $<0.001$ for $\mathrm{F}$ statistics.

\section{DISCUSSION}

Language involves complex interactions of a myriad of variables, complicating the prediction of aphasia prognosis [11]. In this study, we investigated longitudi- nal changes in language function in left-hemispheric ischemic stroke patients, as well as the factors influencing language recovery up until 1 year after stroke onset. Age at onset, education level, initial K-FAST score, initial NIHSS score, and total lesion volume were shown to be important factors influencing recovery from aphasia. Recovery of language function, in terms of increasing KFAST scores from baseline, was dependent on the initial severity of aphasia, and improvement of language function was greater in patients with larger stroke lesions, regardless of involvement of language-related areas.

Previous studies have shown that language recovery after stroke continues throughout a 1-year period; apha- 
(A)

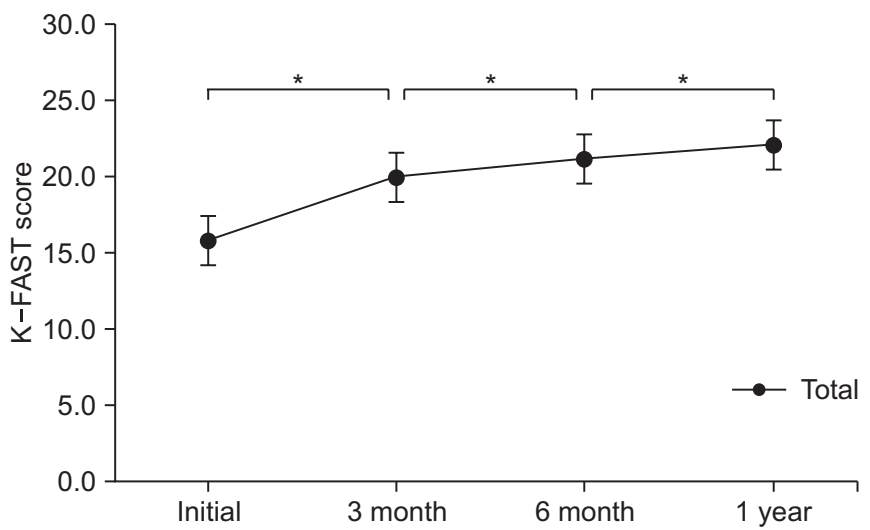

(C)

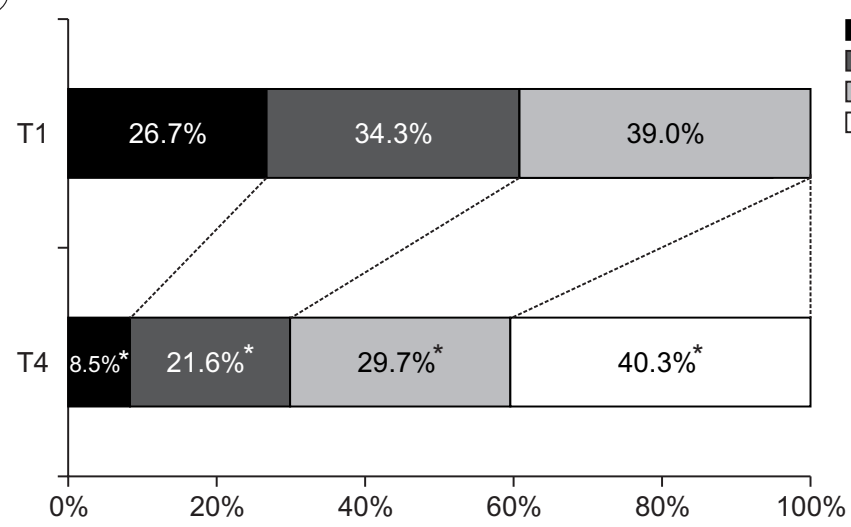

(B)

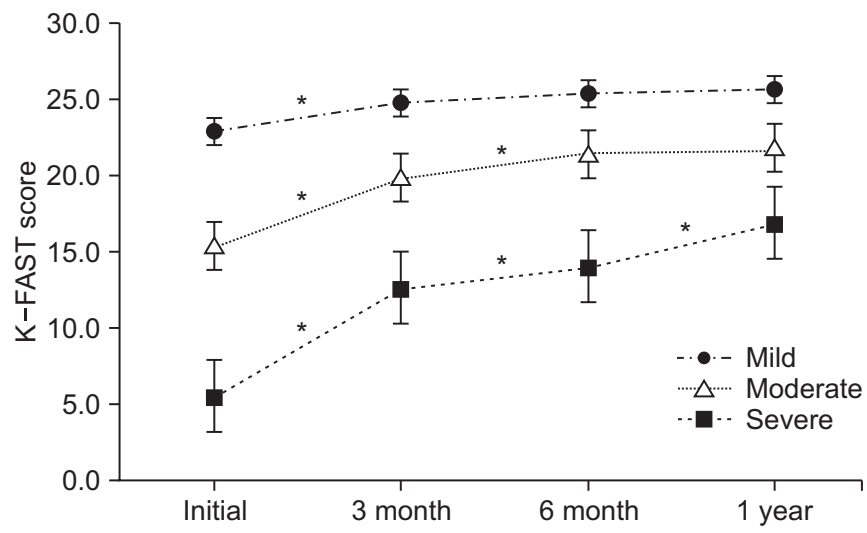

Severe group

Mild group

Moderate group

Normal group

Fig. 3. Changes in the Korean version of the Frenchay Aphasia Screening Test (K-FAST) scores over 12 months after stroke onset in all participants (A) and subgroups by initial severity (B). Significance of improvement in K-FAST scores among time points was analyzed by repeated measures ANOVA. Changes in K-FAST severity group distribution over 12 months after stroke onset (C). Significance of group shifting was analyzed by McNemar test. * $\mathrm{p}<0.05$.

sia improves in $86 \%$ of patients and completely resolves in $74 \%$ of patients by 6 months $[12,13]$. Lazar and colleagues found that patients with significant aphasia after stroke will show improvement to approximately $70 \%$ of their maximum potential recovery by 90 days [14]. This maybe applicable to the overall population; however, the severity of initial aphasia varies inter-individually, and this should be taken into consideration when analyzing recovery trends.

The results of our study are in agreement with previous studies, in that the recovery of language function in the overall population of stroke patients with aphasia continues throughout a 1-year period, and the majority of patients are totally recovered by 1 year. However, our study indicated that aphasia recovery differs according to the initial severity of language deficit. We observed that maximum recovery had occurred by the first 3 months after stroke onset in patients with mild language deficit (initial K-FAST score of 20-25 points) and by 6 months in patients with moderate language deficit (initial K-FAST score of 11-19 points). In contrast, language recovery continued until 1 year in patients with severe language deficit.

The prognosis of aphasia varies widely and is based on very little data; prognosis is often considered to depend on the size of stroke lesion, patient age and education, and the severity and type of deficit [15]. Numerous studies have attempted to define prognostic factors for aphasia after stroke as these factors are essential in determining appropriate treatment intensity and duration. Due to the complex characteristics of language processing, further attempts have been made to determine the prognosis of aphasia based on lesion localization, based on new developments in brain imaging techniques [16]. 
Table 2. Results of univariate linear and multiple regression analysis of independent variables related to improvement in K-FAST scores over 12 months after stroke onset

\begin{tabular}{|c|c|c|c|c|}
\hline & \multicolumn{2}{|c|}{ Univariate analysis } & \multicolumn{2}{|c|}{ Multivariate analysis } \\
\hline & $\beta$ & p-value & $\beta$ & p-value \\
\hline Age & -0.133 & $0.001^{* *}$ & -0.208 & $<0.001^{* * *}$ \\
\hline Sex & -0.593 & 0.602 & - & - \\
\hline Smoking & 0.240 & 0.819 & - & - \\
\hline Alcohol & 1.531 & 0.119 & - & - \\
\hline Hypertension & 1.011 & 0.301 & - & - \\
\hline Diabetes mellitus & -2.251 & 0.056 & - & - \\
\hline Atrial fibrillation & 1.397 & 0.404 & - & - \\
\hline Hyperlipidemia & 1.018 & 0.474 & - & - \\
\hline Obesity & 7.623 & $0.001^{* *}$ & 3.203 & 0.080 \\
\hline Family history & 2.850 & 0.261 & - & - \\
\hline Education level & 1.930 & $0.002^{* *}$ & 1.776 & $0.001^{* *}$ \\
\hline Initial K-FAST score & -0.486 & $0.001^{* * *}$ & -0.611 & $<0.001^{* * *}$ \\
\hline Initial NIHSS initial score & 0.412 & $0.003^{* *}$ & -0.403 & $0.002^{* *}$ \\
\hline Total stroke lesion volume & 0.191 & $0.001^{* * *}$ & 0.075 & $0.023^{* *}$ \\
\hline Language-related cortical region involvement & 3.593 & $0.001^{* *}$ & -0.579 & 0.296 \\
\hline
\end{tabular}

NIHSS, National Institutes of Health Stroke Scale; K-FAST, Korean version of the Frenchay Aphasia Screening Test. ${ }^{* *} \mathrm{p}<0.01,{ }^{* * *} \mathrm{p}<0.001$.

Consistent with previous studies, we found that younger patients with aphasia showed greater improvement than did older patients, and that older age was a negative predictor of language recovery [17-19]. Furthermore, our study agrees with the results of previous studies in that initial stroke severity is associated with poor outcomes $[17,20,21]$. Our results showed that obesity was a positive factor for language deficit improvement in univariate analysis. The obesity paradox in functional recovery of ischemic stroke patients has been mentioned in many studies, and most observational data indicate a survival benefit and better functional outcome in obese patients after stroke [22-25]. However, obesity was not a statistically significant factor in multivariate analysis for aphasia recovery in the current study. Furthermore, BMI, which was used as a measurement of obesity in this study, reflects total lean mass, not adipose tissue; thus, the conclusion of a protective effect of obesity in aphasia recovery after stroke is debatable [23]. A certain body mass may be needed to prevent functional loss in stroke survivors, but this result should not be interpreted such that a higher BMI is better $[23,25]$.

Initial K-FAST score was shown to negatively affect the level of recovery. However, this result should not be interpreted such that patients with mild and moderate aphasia have poor prognosis, since our primary outcome was delta K-FAST, and a ceiling effect could have affected the results in the mild and moderate groups. When additional statistical analysis was performed, we also noticed that the initial K-FAST score was a positive prognostic factor for the 1-year K-FAST score. Therefore, it is conceivable that patients with severe aphasia may have larger improvements throughout a 1-year period, but still have lower final K-FAST scores than the mild and moderate groups.

Large lesion size has been mentioned as a negative prognostic factor for language recovery in previous studies [26-30]. In terms of post-stroke aphasia severity, our study is consistent with previous reports, in that the severity of aphasia increased with an increase in the volume of the stroke lesion, as the average lesion volumes were $5.0 \pm 8.8,5.8 \pm 10.6$, and $13.8 \pm 20.4$ in the mild, moderate, and severe groups, respectively [15]. However, in our study, there was greater improvement in language function in patients with larger stroke volume. Language is currently deemed to involve extended brain regions, and aphasia is considered a multi-dimensional disorder [31]. The finding that larger lesion volume was associated 
with better language improvement may be because large stroke lesions affect global brain function and initially place the patient in the severe aphasia category due to low K-FAST score. Patients with severe aphasia, not due to involvement of the critical language-related cortex but because of global brain dysfunction from large stroke volume, may recover a relatively larger amount of language function; this could be observed as a greater improvement in K-FAST scores in patients with larger stroke lesion volume. In a previous report, Kertesz [15] mentioned a paradoxically positive correlation between the recovery of comprehension and lesion size in Broca's aphasia; hence, further evaluation of lesion volume in specific aphasia types is needed.

Traditionally, stroke involvement in language-related areas of the brain and aphasia type have been thought to affect the prognosis of aphasia, and many studies have been performed [20,32-39]. Some reports have indicated that stroke involving the left STG and Wernicke's area is associated with poor language recovery, and patients showed significant and persistent global aphasia $[35,38]$. In our study, the involvement of Wernicke's area or Broca's area was not related to language recovery. Although our study's primary outcome was delta K-FAST, which may reflect a recovery rate rather than the outcome, when the involvement of language-related areas was further evaluated with the 1-year K-FAST score as a primary outcome, there was still no statistical significance as a prognostic factor.

Rehabilitation duration is one of the key factors that may affect recovery. However, in the KOSCO study, data on amount (hours) of language therapy were obtained only during the first admission. Therefore, data on language therapy hours after discharge from the first hospital admission were not collected. Moreover, since language therapy is not subject to national insurance benefits, total treatment time could not be estimated using the national health insurance data. Therefore, it was difficult to analyze the effect of language therapy in this study. We are planning to investigate the recovery of language function related to intensity of language therapy by undertaking a future intervention study.

\section{CONFLICT OF INTEREST}

No potential conflict of interest relevant to this article was reported.

\section{ACKNOWLEDGMENTS}

This work was supported by grants from the Korea Centers for Disease Control and Prevention (No. 2019E320200) and the National Research Foundation of Korea by the Korean government (MSIP) (No. NRF2017R1A2A1A05000730).

\section{AUTHOR CONTRIBUTION}

Conceptualization: Kim YH, Kim KA. Methodology: Kim KA, Jung SL. Funding acquisition: Kim YH, Kim DY, Kim SY, Kim YT, Kang SH, Choi JY, Chang WH. Project administration: Kim YH, Kim DY, Kim SY, Kim YT, Kang SH, Choi JY, Chang WH. Visualization: Kim KA, Jung SL. Writing - original draft: Kim KA. Writing - review and editing: Kim YH. Approval of final manuscript: all authors.

\section{REFERENCES}

1. Engelter ST, Gostynski M, Papa S, Frei M, Born C, Ajdacic-Gross V, et al. Epidemiology of aphasia attributable to first ischemic stroke: incidence, severity, fluency, etiology, and thrombolysis. Stroke 2006;37:137984.

2. Hoffmann M, Chen R. The spectrum of aphasia subtypes and etiology in subacute stroke. J Stroke Cerebrovasc Dis 2013;22:1385-92.

3. Charidimou A, Kasselimis D, Varkanitsa M, Selai C, Potagas C, Evdokimidis I. Why is it difficult to predict language impairment and outcome in patients with aphasia after stroke? J Clin Neurol 2014;10:75-83.

4. Watila MM, Balarabe SA. Factors predicting poststroke aphasia recovery. J Neurol Sci 2015;352:12-8.

5. Sul B, Kim JS, Hong BY, Lee KB, Hwang WS, Kim YK, et al. The prognosis and recovery of aphasia related to stroke lesion. Ann Rehabil Med 2016;40:786-93.

6. Plowman E, Hentz B, Ellis C Jr. Post-stroke aphasia prognosis: a review of patient-related and strokerelated factors. J Eval Clin Pract 2012;18:689-94.

7. Hamilton RH, Chrysikou EG, Coslett B. Mechanisms of aphasia recovery after stroke and the role of noninvasive brain stimulation. Brain Lang 2011;118:40-50.

8. Chang WH, Sohn MK, Lee J, Kim DY, Lee SG, Shin YI, 
et al. Korean Stroke Cohort for functioning and rehabilitation (KOSCO): study rationale and protocol of a multi-centre prospective cohort study. BMC Neurol 2015;15:42.

9. Bradley WG, Daroff RB, Fenichel GM, Jankovic J. Neurology in clinical practice: principles of diagnosis and management. 4th ed. Philadelphia: Butterworth Heinemann; 2004.

10. Enderby P, Crow E. Frenchay Aphasia Screening Test: validity and comparability. Disabil Rehabil 1996;18: 238-40.

11. Blank I, Balewski Z, Mahowald K, Fedorenko E. Syntactic processing is distributed across the language system. Neuroimage 2016;127:307-23.

12. El Hachioui H, Lingsma HF, van de Sandt-Koenderman MW, Dippel DW, Koudstaal PJ, Visch-Brink EG. Long-term prognosis of aphasia after stroke. J Neurol Neurosurg Psychiatry 2013;84:310-5.

13. Maas MB, Lev MH, Ay H, Singhal AB, Greer DM, Smith WS, et al. The prognosis for aphasia in stroke. J Stroke Cerebrovasc Dis 2012;21:350-7.

14. Lazar RM, Minzer B, Antoniello D, Festa JR, Krakauer JW, Marshall RS. Improvement in aphasia scores after stroke is well predicted by initial severity. Stroke 2010; 41:1485-8.

15. Kertesz A. What do we learn from recovery from aphasia? Adv Neurol 1988;47:277-92.

16. Forkel SJ, Catani M. Lesion mapping in acute stroke aphasia and its implications for recovery. Neuropsychologia 2018;115:88-100.

17. Laska AC, Hellblom A, Murray V, Kahan T, Von Arbin M. Aphasia in acute stroke and relation to outcome. J Intern Med 2001;249:413-22.

18. Pickersgill MJ, Lincoln NB. Prognostic indicators and the pattern of recovery of communication in aphasic stroke patients. J Neurol Neurosurg Psychiatry 1983; 46:130-9.

19. Lendrem W, Lincoln NB. Spontaneous recovery of language in patients with aphasia between 4 and 34 weeks after stroke. J Neurol Neurosurg Psychiatry 1985;48:743-8.

20. Pedersen PM, Vinter K, Olsen TS. Aphasia after stroke: type, severity and prognosis. The Copenhagen aphasia study. Cerebrovasc Dis 2004;17:35-43.

21. Berthier ML. Poststroke aphasia: epidemiology, pathophysiology and treatment. Drugs Aging 2005;22:
163-82.

22. Oesch L, Tatlisumak T, Arnold M, Sarikaya H. Obesity paradox in stroke: myth or reality? A systematic review. PLoS One 2017;12:e171334.

23. Chiquete E, Cante-Brito C, Villarreal-Careaga J, Murillo-Bonilla LM, Rangel-Guerra R, Leon-Jimenez C, et al. Obesity paradox and functional recovery in firstever acute ischemic stroke survivors: the PREMIER study. Rev Neurol 2010;51:705-13.

24. Jang SY, Shin YI, Kim DY, Sohn MK, Lee J, Lee SG, et al. Effect of obesity on functional outcomes at 6 months post-stroke among elderly Koreans: a prospective multicentre study. BMJ Open 2015;5:e008712.

25. Zhao L, Du W, Zhao X, Liu L, Wang C, Wang Y, et al. Favorable functional recovery in overweight ischemic stroke survivors: findings from the China National Stroke Registry. J Stroke Cerebrovasc Dis 2014;23: e201-6.

26. Goldenberg G, Spatt J. Influence of size and site of cerebral lesions on spontaneous recovery of aphasia and on success of language therapy. Brain Lang 1994;47: 684-98.

27. Mazzoni M, Vista M, Pardossi L, Avila L, Bianchi F, Moretti P. Spontaneous evolution of aphasia after ischaemic stroke. Aphasiology 1992;6:387-96.

28. Knopman DS, Selnes OA, Niccum N, Rubens AB, Yock D, Larson D. A longitudinal study of speech fluency in aphasia: CT correlates of recovery and persistent nonfluency. Neurology 1983;33:1170-8.

29. Naeser MA, Baker EH, Palumbo CL, Nicholas M, Alexander MP, Samaraweera R, et al. Lesion site patterns in severe, nonverbal aphasia to predict outcome with a computer-assisted treatment program. Arch Neurol 1998;55:1438-48.

30. Naeser MA, Palumbo CL. Neuroimaging and language recovery in stroke. J Clin Neurophysiol 1994;11:15074.

31. Butler RA, Lambon Ralph MA, Woollams AM. Capturing multidimensionality in stroke aphasia: mapping principal behavioural components to neural structures. Brain 2014;137(Pt 12):3248-66.

32. Alexander MP, Naeser MA, Palumbo C. Broca's area aphasias: aphasia after lesions including the frontal operculum. Neurology 1990;40:353-62.

33. Basso A, Capitani E, Vignolo LA. Influence of rehabilitation on language skills in aphasic patients. A con- 
trolled study. Arch Neurol 1979;36:190-6.

34. Demeurisse G, Demol O, Coekaerts MJ, De Beuckelaer R, Derouck M, Capon A. Quantitative study of the evolution of speech disorders after a stroke (author's transl). Rev Med Brux 1981;2:923-5.

35. Hanlon RE, Lux WE, Dromerick AW. Global aphasia without hemiparesis: language profiles and lesion distribution. J Neurol Neurosurg Psychiatry 1999;66:3659.

36. Jung IY, Lim JY, Kang EK, Sohn HM, Paik NJ. The factors associated with good responses to speech therapy combined with transcranial direct current stimula- tion in post-stroke aphasic patients. Ann Rehabil Med 2011;35:460-9.

37. Kertesz A, McCabe P. Recovery patterns and prognosis in aphasia. Brain 1977;100 Pt 1:1-18.

38. Kertesz A, Lau WK, Polk M. The structural determinants of recovery in Wernicke's aphasia. Brain Lang 1993;44:153-64.

39. Naeser MA, Helm-Estabrooks N, Haas G, Auerbach S, Srinivasan M. Relationship between lesion extent in 'Wernicke's area' on computed tomographic scan and predicting recovery of comprehension in Wernicke's aphasia. Arch Neurol 1987;44:73-82. 